\title{
Development and validation of the CAM Health Belief Questionnaire (CHBQ) and CAM use and attitudes amongst medical students
} Désirée Lie*1 and John Boker ${ }^{2}$

\author{
Address: ${ }^{1}$ Department of Family Medicine and the CAM Education Task Force, College of Medicine, University of California, Irvine, USA and \\ ${ }^{2}$ Office of Educational Affairs, College of Medicine, University of California, Irvine, USA \\ Email: Désirée Lie* - dalie@uci.edu; John Boker - jboker@uci.edu \\ * Corresponding author
}

Published: 12 January 2004

BMC Medical Education 2004, 4:2
Received: 17 September 2003

Accepted: 12 January 2004

This article is available from: http://www.biomedcentral.com/1472-6920/4/2

(c) 2004 Lie and Boker; licensee BioMed Central Ltd. This is an Open Access article: verbatim copying and redistribution of this article are permitted in all media for any purpose, provided this notice is preserved along with the article's original URL.

\begin{abstract}
Background: The need for Complementary and Alternative Medicine (CAM) and holistic approaches in allopathic medical school curricula has been well articulated. Despite increased CAM instruction, feasible and validated instruments for measuring learner outcomes in this content area do not widely exist. In addition, baseline attitudes or beliefs of medical students towards CAM, and the factors that may have formed them, including use of CAM itself, remain unreported.
\end{abstract}

Methods: A 10-item measure (CHBQ - CAM Health Belief Questionnaire) was constructed and administered to three successive classes of medical students simultaneously with the previously validated 29-item Integrative Medicine Attitude Questionnaire (IMAQ). Both measures were imbedded in a baseline needs assessment questionnaire. Demographic and other data were collected on students' use of CAM modalities and their awareness and use of primary CAM information resources. Analysis of CHBQ items was performed and its reliability and criterionrelated validity were established.

Results: Response rate was $96.5 \%$ (272 of 282 students studied). The shorter CHBQ compared favorably with the longer IMAQ in internal consistency reliability. Cronbach's coefficient alpha was 0.75 and 0.83 for the CHBQ and IMAQ respectively. Students showed positive attitudes/beliefs towards CAM and high levels of self-reported CAM use. The majority $(73.5 \%)$ of students reported using at least one CAM modality, and 54\% reported using at least two modalities. Eighty-one percent use the internet as a primary source of information for CAM.

Conclusions: The CHBQ is a practical, valid and reliable instrument for measuring medical student attitudes/beliefs and has potential utility for measuring the impact of CAM instruction. Medical students showed a high self-reported rate of CAM use and positive attitudes towards CAM. Short, didactic exposure to CAM instruction in the first year of medical school did not additionally impact these already positive attitudes. Unlike the IMAQ, which was intended for use with physicians, the CHBQ is generic in design and content and applicable to a variety of learner types. Evaluation measures must be appropriate for specific CAM instructional outcomes. 


\section{Background}

The documented increase in the use of CAM modalities [1-3] by consumers has generated increased attention to curricular integration of this topic by allopathic medical schools $[4,5]$ Entire recent issues of journals have been focused on CAM use [6,7] and CAM education [8]. The number of US medical schools reporting the inclusion of CAM in their curricula has increased from 46 out of 125 schools in 1996-7 [9] to 75 schools in 1998-9 [10] with most US schools now addressing CAM curricula [11]. Focus on CAM instruction has been increased by significant educational funding (the R-25 awards) awarded to medical schools from the National Institutes of Health's National Center for CAM or NCCAM [12]. In addition, the American Medical Association [13] and the Association of American Medical Colleges [8] have actively engaged in discussion of how CAM education should be included in the medical school curriculum and strategies for integrating CAM content into traditional curricula have been suggested $[5,14,15]$. While CAM in the educational setting was originally $[3,9]$ defined as 'unconventional treatment modalities not addressed by allopathic medical schools', more contemporary definitions of CAM and integrative medicine have centered around a holistic approach to health care taking into account alternative healing systems, beliefs and individual modalities of treatment not usually offered in a traditional Western health care system. Classifications of CAM modalities have differed but a generally accepted schema was introduced by the NCCAM [12] and is in common use.

An interdisciplinary CAM Education Task Force at University of California, Irvine (UCI) College of Medicine was charged in 2001 with the design, implementation and evaluation of new longitudinal CAM instruction presented as part of the College's existing undergraduate medical school curriculum. The 26-member Task Force was comprised of representatives from multiple stakeholder groups: medical students; multidisciplinary physician faculty and educators; health professionals representing nursing, pharmacy, library sciences and basic science disciplines; CAM practitioners (chiropractors, dietitian, herbalist, massage therapist, acupuncturists, and Oriental Medicine practitioners); CAM school faculty; and CAM researchers.

Like many US medical schools, UCI offers a hybrid curriculum for its 4-year curriculum, with a predominance of lecture-based courses in the first two years, and problembased learning a part of the clinical Patient Doctor (PD) course. Clinical clerkships are offered in years 3 and 4 of the curriculum. In 2002-3, required CAM instruction was integrated as a lecture and small group exercise into the first year PD course. The PD course is the major curriculum experience where medical students learn interview- ing, physical diagnosis and clinical reasoning skills and the fundamentals of professional behavior and values.

Despite a demonstration of the need for CAM instruction and a willingness to commit resources to CAM curricular development, limited data and research exist to guide the assessment of students' acquisition of CAM skills, knowledge and attitudes/beliefs. The evaluation of CAM curricular impact is complicated by the perceived heterogeneity of baseline attitudes or beliefs toward CAM and integrative medicine. Since new curriculum must compete for existing institutional time and resources, it is imperative to document and systematically chart progression of student learning outcomes as the primary method to determine optimal strategies to achieve effective CAM instruction.

The Integrative Medicine Attitude Questionnaire (IMAQ) [16] previously was designed to measure physicians' attitudes or beliefs towards integrative medicine in their own medical practice. However, pilot testing with the IMAQ as a potential instructional outcome measure suggested that the number of IMAQ items (29) and the length and complexity of its individual items was problematic and impractical in the context of repeated administrations to measure instructional outcomes. Furthermore, its content is specific to physicians in practice and not necessarily to medical students during instruction. Other health belief and health perception questionnaires $[17,18]$ do not directly address CAM instructional outcomes. The primary objective of this project was to construct and validate a short, practical instrument to measure attitudes/ beliefs among medical students. A secondary objective was to establish a baseline for evaluating longitudinal learning outcomes after introducing enhanced CAM instruction.

\section{Methods}

\section{Study Sample}

Respondents were students at the UCI College of Medicine. Class size at UCI for each of the three classes surveyed is 92 to 97 medical students per year. Included were 92 first-year (MS 1) and two separate second-year medical student classes (MS 2). There was a total of 190 MS 2; 97 in one group and 93 in the other. All medical students in the 3 classes were surveyed at different times in the academic years 2001-3. MS 1 were surveyed during the first six weeks after school entry (fall of 2002) as an in-class exercise and before exposure to any CAM instruction. One MS 2 class was surveyed during the last six weeks of their second year (spring of 2003). The other MS 2 class was surveyed midway through their second year (winter of 2002). The survey of both MS 2 classes occurred after exposure to three hours of didactic CAM instruction, 
using a panel consisting of patients and CAM providers, in the required year 1 Patient Doctor (PD) course.

\section{Study Design}

Measures

The experimental 10-item CAM Health Belief Questionnaire (CHBQ) was designed and constructed by the interdisciplinary CAM Education Task Force chaired by the lead author. Item content for the CHBQ, covering both CAM issues and attitudes toward a holistic approach to the patient, was identified and agreed upon by consensus after a thorough literature review. The literature review was conducted by a search of the PubMed, Cochrane Library, ERIC and Psychlit databases using combinations of the terms "Complementary and Alternative Medicine," "Integrative Medicine," "education," "teaching," "surveys," "medical students," "attitudes" and "faculty." In addition, a manual search for conference abstracts and unpublished reports was conducted through direct communication with authors of articles identified, with principal investigators of the NCCAM R-25 initiative, and participation by the lead author in three CAM conferences. This process resulted in the identification of four papers [16-19] reporting CAM attitude scales, of which only the 29-item IMAQ [16] had been validated by administration to a group of internists. This iterative review process was the primary method for establishing the content validity of the CHBQ items. (The CHBQ items are shown in Additional file 1.)

The experimental CHBQ items were framed in the sevenpoint, Likert-type rating scale format (where 1 = "Absolutely Disagree," and 7 = "Absolutely Agree") for consistency with the IMAQ items. Responses to all CHBQ and IMAQ items were scored so that a higher response indicated greater endorsement. CHBQ and IMAQ total scale scores were computed by summing across their respective constituent rating items. Three CHBQ items were worded negatively to minimize the acquiescence response set (i.e., the tendency of respondents to reply in a consistent manner using only part of the rating scale range). Directions to the CHBQ respondents were: "Please read and respond to each of the 10 statements below by circling the number that most agrees with your beliefs."

A written "CAM needs assessment" questionnaire was constructed [see Additional file 1] by adapting items from existing instruments [16-18] and adding items about CAM use. First, respondents' self-reported use of 14 common CAM modalities was requested. Students were asked to check off all relevant boxes in response to the questions "ever used/would use/currently use, would recommend/ ever recommended to patients" for each of the modalities listed. Modalities were defined in the categories listed by the NCCAM [11] but these definitions, per se, were not provided in the survey. The category of "Curanderismo" (not in the NCCAM categories) was included because of its relevance to the California Latino population. The MS 1 questionnaire contained a $15^{\text {th }}$ CAM modality - "vitamin/mineral supplements" which was dropped from the subsequent surveys because of disagreement about the inclusion of this category as alternative medicine. Second, awareness and use of primary online and other CAM information resources were assessed. Both item sets elicited binary (Yes/No) response sets. Third, attitudes/beliefs were assessed with the 29-item IMAQ and complemented by the experimental 10-item CHBQ.

\section{Data collection}

All students were asked to anonymously and voluntarily complete the structured written questionnaire, which was presented as a baseline assessment of their perceptions about CAM. The questionnaire was administered by a staff member who was not involved in the students' instruction or evaluation. Data were collected at one sitting per class lasting about 20 minutes. No incentives were given for completion of questionnaires. The entire project had Institutional Review Board (IRB) approval.

\section{Data analysis}

Analyses were done using SPSS version 11.5 software (SPSS, Inc., Chicago, Illinois). First, descriptive statistics for all variables across all respondents were computed. The frequency that each CAM modality was used and the total number of modalities used was compared across the three classes. The frequency of awareness and use of each primary CAM information resource was documented. Total scale scores for the CHBQ and IMAQ were computed, by summing and averaging across each measure's constituent rating items, and the resulting mean scores for each cohort were compared. Between-class comparisons were made either by one-way analysis of variance, independent t-tests, Wilcoxon-Mann-Whitney tests, or $\chi^{2}$ tests, as appropriate for the dependent variable's underlying metric and distribution. Associations among survey variables were examined with Pearson product-moment or Spearman rank-order correlation coefficients. CHBQ and IMAQ item responses were analyzed to produce item means and standard deviations, corrected item-total scale score correlations (i.e., discrimination indices), Cronbach's coefficient $\alpha$ reliabilities for scale scores, and coefficient $\alpha$ reliability obtained after removing a constituent rating item from its respective scale score. For the $\mathrm{CHBQ}$, the Spearman-Brown formula was used to compare its reliability to that of the IMAQ which contained three times as many items and was known from prior use to have moderately high reliability $(\geq .80)$. Validity coefficients for each experimental CHBQ item were calculated by correlating each of the item scores with the total IMAQ scale score. Criterion-related validity of the CHBQ total 
Table I: Demographics of medical students responding to a survey on Complementary and Alternative Medicine (CAM) [see Additional file I], by survey administration to three successive classes.

\begin{tabular}{|c|c|c|c|c|c|c|c|}
\hline \multirow[t]{3}{*}{ Survey Class } & \multirow{3}{*}{$\begin{array}{c}\text { Response } \\
\text { Rate }\end{array}$} & \multicolumn{6}{|c|}{ Demographic Measures* } \\
\hline & & \multicolumn{2}{|c|}{ Age } & \multicolumn{2}{|c|}{ Gender } & \multicolumn{2}{|c|}{ Ethnicity } \\
\hline & & 20-29 & $\geq 30$ & Female & Male & $\begin{array}{c}\text { Caucasia } \\
n\end{array}$ & Other \\
\hline MS I at entry to medical school & $87 / 92$ & 98.7 & 1.3 & 48.5 & 51.5 & 38.1 & 61.9 \\
\hline MS 2 at midpoint of second year of medical school & $88 / 93$ & 91.9 & 7.1 & 44.7 & 55.3 & 42.0 & 58.0 \\
\hline MS 2 at end of second year of medical school & $97 / 97$ & 85.6 & 14.4 & 50.7 & 49.3 & 49.4 & 50.6 \\
\hline Total & $272 / 282$ & 91.9 & 8.1 & 47.8 & 52.2 & 43.0 & 57.0 \\
\hline
\end{tabular}

*Due to missing data, $n$ may be smaller than 272 for some variables.

scale scores was examined by its correlation with the IMAQ scale scores, CAM modality usage and CAM information source usage.

\section{Results}

\section{Respondents and their characteristics}

The response rates were $94.6 \%$ (87/92) for MS 1, 100\% (97/97) for the first MS 2 cohort, and $94.6 \%$ (88/93) for the second MS 2 cohort. Thus, the overall response rate across three class cohorts was $96.5 \%$ (272/282). Table 1 shows the demographic characteristics of responding students in the three cohorts. There were no differences in gender distribution $(p=.75)$. Overall, there were $47.8 \%$ female and 52.2\% male respondents. Most students $(91.9 \%)$ fell into the 20-29 year-old age range. However, the MS 2 surveyed at the end of their second academic year had a disproportionate percentage of students who were $\geq 30$ years old $(14.4 \%$ v. $7.1 \%$ in the other MS 2 cohort and $1.3 \%$ among MS $1 ; p=.006$ ). The primary ethnic group of each class was Caucasian (45.3\%), with Asian (Oriental and Indian Subcontinent) the next most represented group (35.6\%). Cohorts did not differ in ethnicity distribution $(p=.30)$. Most students had taken science as the major subject in premedical school $(80.4 \%$ of MS 1 , $78.7 \%$ of MS 2); the remaining students took humanities as their major subject before medical school. The mean grade point averages for students at medical school entry were 3.7 for MS 1 and 3.6 for MS 2 on a 0.0 to 4.0 gradepoint scale.

\section{CAM modality use}

Across the three classes, $73.5 \%$ of students reported use of at least one CAM modality (excluding vitamin/mineral supplements); $19.5 \%$ used just one CAM modality, and $54.0 \%$ used two or more modalities. The modalities reported as most frequently used were: massage $(43.0 \%)$; meditation/yoga/relaxation/imagery (40.4\%); and spirit- uality (35.3\%). Vitamin and mineral supplements were used by $64.4 \%$ of MS 1 , which was the only cohort asked about this modality. Self-reported use of each of the CAM modalities by responding students, both overall and by class cohort, is shown in Table 2. There were no betweencohort differences in either the frequency of using any CAM modality ( $p$-values ranged from .14 to .90) or in the mean total number of modalities used $(2.4 \pm 2.5 ; p=.24)$.

\section{Awareness and use of CAM information resources}

The Internet was identified as the chief CAM information source ( $81.3 \%$ of all respondents), followed by journals $(40.8 \%)$, books $(37.5 \%)$, health databases $(28.3 \%)$, and videos (2.6\%). Most (91.5\%) respondents reported being aware of PubMed [20] as an online information resource, consistent across cohorts $(p=.09)$. However, MS 1 reported greater awareness of all the other online CAM information resources, in comparison to their MS 2 peers completing their second academic year: Cochrane Library ( $85.1 \%$ v. $67.0 \% ; p=.016)$; German Commission E Monographs: Therapeutic Guide to Herbal Medicine (17.2\% v. $2.1 \% ; p=.002)$; Combined Health Information Database $(12.6 \%$ v. $2.1 \% ; p=.021)$; and NCCAM Website $(26.4 \%$ v. $8.2 \% ; p=.003$ ). All cohorts provided similar reports about where they seek evidence-based and other information about CAM ( $p$-values of .12 to .97 ).

\section{IMAQ and CHBQ scale score reliabilities}

The internal consistency reliabilities of CAM attitude/ belief scale scores, measured by Cronbach's coefficient $\alpha$, were 0.83 for the 29-item IMAQ and 0.75 for the 10 -item CHBQ. Because the CHBQ scale score was based on fewer items, its stepped-up reliability was estimated by the Spearman-Brown formula and compared with the IMAQ scale score reliability, which was based on almost three times as many items. Assuming that parallel items were constructed and added to the CHBQ, a total of about only 
Table 2: Use of Complementary and Alternative Medicine (CAM) modalities reported in a survey of three successive medical student classes, by survey administration.

\begin{tabular}{|c|c|c|c|c|}
\hline \multirow[t]{2}{*}{ CAM Modality Used (\%)* } & \multicolumn{4}{|c|}{ Survey Class } \\
\hline & $\begin{array}{l}\text { MS I at entry to medical } \\
\text { school }(n=87)\end{array}$ & $\begin{array}{l}\text { MS } 2 \text { at midpoint of } 2^{\text {nd }} \text { year of } \\
\text { medical school }(n=88)\end{array}$ & $\begin{array}{l}\text { MS } 2 \text { at end of } 2^{\text {nd }} \text { year of } \\
\text { medical school }(n=97)\end{array}$ & $\begin{array}{l}\text { All medical students } \\
\qquad(n=272)\end{array}$ \\
\hline Meditation & 46.0 & 43.2 & 33.0 & 40.4 \\
\hline Massage & 43.7 & 46.6 & 39.2 & 43.0 \\
\hline Spirituality & 42.5 & 35.2 & 18.9 & 35.3 \\
\hline Herbals & 36.8 & 37.5 & 27.8 & 33.8 \\
\hline Chiropractic & 26.4 & 17.0 & 15.5 & 19.5 \\
\hline Traditional Oriental & 12.6 & 11.4 & 15.5 & 13.2 \\
\hline T'ai Chi & 10.3 & 6.8 & 10.3 & 9.2 \\
\hline Homeopathy & 9.2 & 11.4 & 10.3 & 10.3 \\
\hline Biofeedback & 9.2 & 11.4 & 4.1 & 8.1 \\
\hline Hypnosis & 8.0 & 8.0 & 4.1 & 6.6 \\
\hline Ayurveda & 6.9 & 4.5 & 6.2 & 5.9 \\
\hline Osteopathy & 6.9 & 6.8 & 4.1 & 5.9 \\
\hline Therapeutic Touch & 5.7 & 4.5 & 4.1 & 4.8 \\
\hline Curanderismo & 2.3 & 1.1 & 2.1 & 1.8 \\
\hline Vitamins ${ }^{\dagger}$ & 64.4 & -- & -- & -- \\
\hline
\end{tabular}

*Due to missing data, $n$ may be smaller than 272 for some variables. Iltem asked only in the MS I survey.

17 items are required to achieve the same level of reliability as the much longer IMAQ.

\section{Psychometrics of the CHBQ items}

The results obtained from the item analysis of the CHBQ are shown in Table 3. Mean item scores ranged from a low of 4.1 to a high of 5.9 on the 7-point scale. Although medical students actually responded using the entire range of possible scale values on all CHBQ items, the associated item means suggest that responses were skewed toward the higher end of the response scale. The highest mean (5.9) item score was, "A patient's expectations, health beliefs, and values should be integrated into the patient care process." The lowest items mean (4.1) was a reversescored item, "Treatments not tested in a scientifically recognized manner should be discouraged." The standard deviations ranged from 1.3 to 1.6 . Both the item-total correlations (range of .23 to .57) and the item validity coefficients (range of .25 to .57) were all positive and were statistically significant $(p<.0005)$. The finding of all positive item-total correlations and validity coefficients supports the direction in which the CHBQ items were scored. The fact that all such observed values were statistically significant indicates that each $\mathrm{CHBQ}$ item separately makes a significant and valid contribution to the CHBQ composite scale score. This is affirmed by examination of the last column in Table 3. In no case does deleting any item increase the reliability of the CHBQ scale score.

\section{CAM attitudes and beliefs}

The IMAQ grand mean score was $142.5( \pm 17.0$; range $91.0,181.0$; 95\% C.I. 140.5, 144.6). The IMAQ grand mean exceeded the hypothetical scale score midpoint of
116 (i.e., a rating value of 4 times 29 items), reflecting students' overall positive attitudes/beliefs toward CAM ( $p<$ 0.0005 ; 95\% C.I. of difference 24.5, 28.6). No betweencohort difference was found on mean IMAQ total scale scores $(p=.25)$. The CHBQ grand mean was $47.8( \pm 8.1$; range 24.0-68.0; 95\% C.I. 46.8, 48.8). The CHBQ grand mean also exceeded its hypothetical scale midpoint of 40 , reaffirming the positive CAM attitudes/beliefs found on the IMAQ ( $p<0.0005 ; 95 \%$ C.I. of difference $6.8,8.8)$. Students in the three cohorts did not differ on their mean CHBQ total scores $(p=.23)$. Student cohort scores for IMAQ and CHBQ are represented in Table 4. The correlation between IMAQ and CHBQ total scale scores was $0.71(p<0.0005)$, indicating that they overlapped considerably in the underlying construct that they measured (i.e., each accounted for about $50 \%$ of the variance in the other measure's scores), but that each measured somewhat different aspects of the same domain.

No IMAQ or CHBQ items had means $\leq 3.0$ ("Disagree"); $51.7 \%$ and $30.0 \%$ of items on each respective scale had means $\geq 5.0$ ("Agree"). Item analysis results for CHBQ items are summarized in Table 4.

Comparable results were obtained for the IMAQ items, where mean scores ranged from a low of 3.2 to a high of 6.1 on the 7 -point scale (standard deviations ranged from 1.1 to 1.7 ). Respondents used the entire range of possible rating scale values on 27 of the IMAQ items. Three IMAQ items had mean scores that exceeded 5.9. They were: (a) a reverse-scored item, "The spiritual beliefs and practices of patients play no important role in healing" (mean=6.1); (b) "A strong relationship between patient and physician 
Table 3: The Complementary and Alternative Medicine (CAM) Health Belief Questionnaire (CHBQ): Items means, standard deviations, item-total correlations, validity coefficients, and coefficient alphas if the item is deleted from the composite scale score. Data for three successive classes of medical students.

\begin{tabular}{|c|c|c|c|c|c|}
\hline Item Content & Mean ${ }^{a}$ & $\begin{array}{l}\text { Standard } \\
\text { Deviation }\end{array}$ & $\begin{array}{l}\text { Item-Total } \\
\text { Correlation }\end{array}$ & $\begin{array}{c}\text { Validity } \\
\text { Coefficientc }\end{array}$ & $\begin{array}{l}\text { Alpha if Item is } \\
\text { Deleted }^{d}\end{array}$ \\
\hline $\begin{array}{l}\text { The physical and mental health are maintained by an } \\
\text { underlying energy or vital force. }\end{array}$ & 4.4 & 1.6 & .57 & .47 & .70 \\
\hline $\begin{array}{l}\text { Health and disease are a reflection of balance } \\
\text { between positive life-enhancing forces and negative } \\
\text { destructive forces. }\end{array}$ & 4.3 & 1.5 & .56 & .39 & .71 \\
\hline $\begin{array}{l}\text { The body is essentially self-healing and the task of a } \\
\text { health care provider is to assist in the healing } \\
\text { process. }\end{array}$ & 4.7 & 1.5 & .36 & .25 & .74 \\
\hline $\begin{array}{l}\text { A patient's symptoms should be regarded as a } \\
\text { manifestation of a general imbalance or dysfunction } \\
\text { affecting the whole body. }\end{array}$ & 4.6 & 1.4 & .49 & .34 & .72 \\
\hline $\begin{array}{l}\text { A patient's expectations, health beliefs and values } \\
\text { should be integrated into the patient care process. }\end{array}$ & 5.9 & 1.3 & .23 & .35 & .75 \\
\hline $\begin{array}{l}\text { Complementary therapies are a threat to public } \\
\text { health.e }\end{array}$ & 5.5 & 1.5 & .37 & .57 & .74 \\
\hline $\begin{array}{l}\text { Treatments not tested in a scientifically recognized } \\
\text { manner should be discouraged. }{ }^{\circ}\end{array}$ & 4.1 & 1.6 & .27 & .32 & .75 \\
\hline $\begin{array}{l}\text { Effects of complementary therapies are usually the } \\
\text { result of a placebo effect. }\end{array}$ & 4.5 & 1.4 & .33 & .44 & .74 \\
\hline $\begin{array}{l}\text { Complementary therapies include ideas and methods } \\
\text { from which conventional medicine could benefit. }\end{array}$ & 5.4 & 1.3 & .45 & .53 & .73 \\
\hline $\begin{array}{l}\text { Most complementary therapies stimulate the body's } \\
\text { natural therapeutic powers. }\end{array}$ & 4.5 & 1.3 & .50 & .33 & .72 \\
\hline
\end{tabular}

a All items used a 7-point response scale, with I = "Absolutely Disagree" and 7 = "Absolutely Agree." b Product-moment correlation corrected by excluding the item score from the total score. All correlations are statistically significant $(p<.0005)$. c Product-moment correlation using IMAQ scale score as the criteria score. All correlations are statistically significant $(p<.0005)$. d Some statistics calculated with student sample size $<272$ because of missing data. e Item responses were reverse scored so a higher value indicated greater endorsement.

is an extremely valuable therapeutic intervention that leads to improved outcomes" (mean=6.0; and (c) "Quality of life measures are of equal importance as disease specific outcomes in research" (mean= 5.9). The lowest IMAQ mean (3.2) was a reverse-scored item, "The physician's role is primarily to promote the health and healing of the physical body."

Students posting higher IMAQ or CHBQ total scale scores tended to be those who used more CAM modalities ( $\mathrm{r}=$ .30 and .39 , respectively; $p<.0005$ ). Higher IMAQ and CHBQ scores also were associated with having used more CAM information resources $(r=.24$ and $.22 ; p<.0005)$. There was a weak but statistically significant correlation between gender and scores on the IMAQ scale $(r=.20$; $p$ $=.002)$ and on the CHBQ $(\mathrm{r}=.16 ; \mathrm{p}=.01)$, with females posting somewhat higher scores overall. All other correlations among IMAQ, CHBQ, and other variables studied were not statistically significant.

\section{Conclusions and Discussion}

This study was conducted at one medical school for three medical student classes. While this population provided sufficient data for validation of the CHBQ, the reported results on use of CAM modalities, informational sources and CAM beliefs/attitudes are specific to these cohorts. Limitations of the study include: a different method of surveying students for CAM modality use compared to the US national telephone survey reports of the general population $[2,3]$, and lack of comparison with another medical school. In addition, we chose not to define each of the 14 listed CAM modalities in the survey to maintain brevity and compliance with completion, and some overlap of choices may have occurred. For example, the modality of prayer or intercessory prayer could be categorized as either "spirituality" or "meditation." However we believe that since students would have chosen only one category for each modality used, this would not have resulted in overreporting of self-use.

One aim of this study was to validate and test the feasibility of a new measure of medical student attitudes/beliefs towards CAM use and practice. The 10-item CHBQ had similar measurement properties to the 29-item IMAQ. Responses to both measures overlapped considerably, suggesting that each measured the same underlying con- 
Table 4: IMAQ and CHBQ descriptive scale score statistics for three successive medical student classes.

\begin{tabular}{|c|c|c|c|c|c|c|c|c|}
\hline \multirow[t]{2}{*}{ Survey Class } & \multirow[t]{2}{*}{$n$} & \multirow[t]{2}{*}{ Mean } & \multirow{2}{*}{$\begin{array}{l}\text { Standard } \\
\text { Deviation }\end{array}$} & \multicolumn{2}{|c|}{ Range } & \multicolumn{3}{|c|}{ Percentiles } \\
\hline & & & & Min. & $\operatorname{Max}$ & $25^{\text {th }}$ & $50^{\text {th }}$ & $75^{\text {th }}$ \\
\hline \multicolumn{9}{|c|}{ MS I at entry to medical school } \\
\hline IMAQ & 87 & 142.8 & 18.3 & 91 & 179 & 130.5 & 143.0 & 158.0 \\
\hline $\mathrm{CHBQ}$ & 85 & 48.4 & 8.9 & 27 & 64 & 40.5 & 49.0 & 56.3 \\
\hline \multicolumn{9}{|c|}{$\begin{array}{l}\text { MS } 2 \text { at midpoint of second year of } \\
\text { medical school }\end{array}$} \\
\hline IMAQ & 85 & 140.1 & 18.5 & 91 & $|8|$ & 126.0 & 140.0 & 155.5 \\
\hline $\mathrm{CHBQ}$ & 85 & 46.6 & 8.6 & 24 & 68 & 40.0 & 46.0 & 53.0 \\
\hline \multicolumn{9}{|c|}{$\begin{array}{l}\text { MS } 2 \text { at end of second year of medical } \\
\text { school }\end{array}$} \\
\hline IMAQ & 96 & 144.4 & 14.2 & 112 & 181 & 136.0 & 144.0 & 152.8 \\
\hline $\mathrm{CHBQ}$ & 97 & 48.3 & 6.7 & 29 & 65 & 44.0 & 48.0 & 52.5 \\
\hline \multicolumn{9}{|l|}{ Total } \\
\hline IMAQ & 268 & 142.5 & 17.0 & 91 & 181 & $13 \mid .0$ & 143.0 & I 55.0 \\
\hline $\mathrm{CHBQ}$ & 267 & 47.8 & 8.1 & 24 & 68 & 42.0 & 48.0 & 53.0 \\
\hline
\end{tabular}

struct of attitudes toward the use of complementary and alternative therapies in the setting of holistic health care and alternative health belief systems. The CHBQ has the advantage of being generic to health professionals and not limited to physicians for measuring CAM attitudes/ beliefs. Therefore it may be used for residency, nursing and CAM practitioner education, although separate validation studies for trainees in other disciplines remain to be done. The brevity of the CHBQ increases its practicality for repeated administrations and may facilitate greater compliance, ease of analysis, and a higher response rate, all of which contribute to the acquisition of more reliable and valid educational outcome evaluation data.

Medical students use CAM modalities at a self-reported rate higher than recently reported in the general US population $[2,3]$. However, the methods of surveying the populations are different. We used a written survey in an educational setting whereas the US general population studies used telephone surveys of randomly selected households. This study revealed no differences in overall use of CAM modalities by MS 1 and MS 2 who are at different stages of their medical school training. More than $73 \%$ of students in this study reported self-use of at least one modality, compared to $42 \%$ of the US population surveyed in 1997 [2]. The modalities most commonly used are similar to those identified by the US population: herbal medicine, massage, and megavitamins [2]. The reasons why US patients use CAM were explored and reported in 1998 [21]. In that study, the majority of patients seeking CAM therapies was described as being more educated, reporting poorer health, and selecting CAM therapies not because of dissatisfaction with conventional therapies, but because alternative therapies were more congruent with their values and health beliefs. In this study, the reasons why our students use CAM thera- pies at a higher rate than the general population were not examined.

The medical students studied are highly likely to seek information about CAM from online resources, particularly PubMed [20]. It is difficult to account for the greater awareness of a variety online CAM resources by MS 1 compared to MS 2. This may represent a "recency effect" of a medical informatics class for MS 1 that included CAM online data sources. Since the MS 2 received the same informatics instruction in their first year, this suggests a need to reinforce the teaching of online information CAM resources in year 2 of the curriculum.

The three student class samples presented with similar characteristics, and they represented a rather homogenous group of learners. MS 2 had received three hours of required didactic CAM instruction within the PatientDoctor course. This curriculum appeared not to have additionally impacted an already positive attitude towards CAM education and use. One shortcoming is that we did not collect information on changes in CAM knowledge and skills in the three classes studied to demonstrate an increase in these domains of learning. The finding of positive attitudes/beliefs towards CAM for all classes is useful for guiding future CAM curriculum development. Whether the positive attitudes are related to certain student demographics (such as diverse ethnicity, origin from California, or gender) specific to the 3 classes is yet to be determined. Only gender was significantly correlated with IMAQ and CHBQ total scale scores, and those correlations were small. Ethnicity was not a significant correlate. Future comparisons with medical schools having different student characteristics are anticipated and will be revealing. It is concluded that the already positive perceptions students bring at entry to medical school are maintained 
through a first year curriculum of predominantly basic science courses and minimal formal CAM instruction.

Future new CAM curricula will focus on knowledge and skill acquisition, such as competencies for interviewing patients for CAM use and health beliefs, and skills for searching and locating evidence on CAM modalities, rather than to change already positive CAM attitudes/ beliefs. Measuring the outcomes of instruction should include and account for the effects of attitudes/beliefs on learners' acquisition of competencies. Thus, the relatively brief and easy-to-administer CHBQ will have high utility.

In summary, this study showed that students enter our medical school with positive attitudes/beliefs towards CAM practice and exhibit a high level of self-reported use of CAM modalities, above that observed in the general US population. Students have a high rate of online information-seeking behavior in relation to CAM use, but this is mostly limited to one database. The short CHBQ has the potential to measure student attitudes/beliefs. In addition, the CHBQ has potential use in other health professions education settings. Given the paucity of educational tools for measuring the impact of new CAM curricula, the CHBQ will provide a useful start to CAM attitude/belief assessment. The need remains to carefully develop and validate methods for evaluating other instructional outcomes such as CAM knowledge and skill acquisition.

\section{List of Abbreviations Used \\ CAM Complementary and Alternative Medicine}

\section{CHBQ CAM Health Belief Questionnaire}

IMAQ Integrative Medicine Attitude Questionnaire

IRB Institutional Review Board

MS 1 First year medical student

MS 2 Second year medical student

\section{Competing Interests}

None declared.

\section{Authors' Contributions}

Désirée Lie co-designed the study, performed the literature review, collected the data and co-authored the manuscript. John Boker co-designed the study, performed the data analysis, and co-authored the manuscript.

\section{Additional material}

\section{Additional File 1}

CAMsurvey, PDF format, Survey of Health Care Use and Practice, $a$ CAM needs assessment questionnaire.

Click here for file

[http://www.biomedcentral.com/content/supplementary/14726920-4-2-S1.doc]

\section{Acknowledgements}

The Susan Samueli Center for Complementary and Alternative Medicine at the University of California, Irvine supported this work. The CAM Education Task Force contributed to the development and pilot testing of the $\mathrm{CHBQ}$ and provided manuscript review and approval.

\section{References}

I. Eisenberg DM: Advising patients who seek alternative medical therapies. Ann Intern Med 1997, I 27:6I-69.

2. Eisenberg DM, Davis RB, Ettner SL, Appel S, Wilkey S, Van Rompay $M$, Kessler RC: Trends in alternative medicine use in the United States, 1990-1997: results of a follow-up national survey. JAMA 1998, 280: I569-I575.

3. Eisenberg DM, Kessler RC, Foster C, Norlock FE, Calkins DR, Delbanco TL: Unconventional medicine in the United States. Prevalence, costs, and patterns of use. N Engl J Med 1993, 328:246-252.

4. Wetzel MS, Kaptchuk TJ, Haramati A, Eisenberg DM: Complementary and alternative medical therapies: implications for medical education. Ann Intern Med 2003, | 38: $191-196$.

5. Frenkel M, Arye EB: The growing need to teach about complementary and alternative medicine: questions and challenges. Acad Med 200I, 76:25I-254.

6. Lundberg G: Alternative Medicine. JAMA 1998, 280:1549-1640.

7. British Medical Journal 1997.

8. Whitcomb M: Complementary, Alternative, and Integrative Medicine. Acad Med 2002, 77:845-941.

9. Wetzel MS, Eisenberg DM, Kaptchuk T]: Courses involving complementary and alternative medicine at US medical schools. JAMA 1998, 280:784-787.

10. Barzansky B, Jonas HS, Etzel SI: Educational programs in US medical schools, 1999-2000. JAMA 2000, 284: I I I4-I I 20.

II. Bhattacharya B: M.D. programs in the United States with complementary and alternative medicine education opportunities: an ongoing listing. J Altern Complement Med 2000, 6:77-90.

12. NCCAM, National Institutes of Health [http:// www.nccam.nih.gov]

13. American Medical Association Council on Medical Education June 1997: Encouraging medical student education in complementary health care practices. Chicago, IL, American Medical Association; 1977.

14. Carlston M, Stuart MR, Jonas W: Alternative medicine instruction in medical schools and family practice residency programs. Fam Med 1997, 29:559-562.

15. Kligler B, Gordon A, Stuart M, Sierpina V: Suggested curriculum guidelines on complementary and alternative medicine: recommendations of the Society of Teachers of Family Medicine Group on Alternative Medicine. Fam Med 2000, 32:30-33.

16. Schneider CD, Meek PM, Bell IR: Development and validation of IMAQ: Integrative Medicine Attitude Questionnaire. BMC Med Educ 2003, 3:5.

17. Hopper I, Cohen M: Complementary therapies and the medical profession: a study of medical students' attitudes. Altern Ther Health Med 1998, 4:68-73.

18. Chez RA, Jonas WB, Crawford C: A survey of medical students' opinions about complementary and alternative medicine. Am J Obstet Gynecol 200I, 185:754-757.

19. Kreitzer MJ, Mitten D, Harris I, Shandeling J: Attitudes toward CAM among medical, nursing, and pharmacy faculty and stu- 
dents: a comparative analysis. Altern Ther Health Med 2002, 8:44-7, 50-3.

20. PubMed, National Library of Medicine [http://
[ www.ncbi.nih.gov/entrez/query.fcgi]

21. Astin JA: Why patients use alternative medicine: results of a national study. JAMA 1998, 279:1548-1553.

\section{Pre-publication history}

The pre-publication history for this paper can be accessed here:

http://www.biomedcentral.com/1472-6920/4/2/prepub

Publish with Bio Med Central and every scientist can read your work free of charge

"BioMed Central will be the most significant development for disseminating the results of biomedical research in our lifetime. " Sir Paul Nurse, Cancer Research UK

Your research papers will be:

- available free of charge to the entire biomedical community

- peer reviewed and published immediately upon acceptance

- cited in PubMed and archived on PubMed Central

- yours - you keep the copyright

Submit your manuscript here:

http://www.biomedcentral.com/info/publishing_adv.asp 